\title{
Influence of Information System Factors to Operational Performance Sustainability of UAE Manufacturing Sector
}

\author{
Darwish Ahmed Darwish Abdulla Lari ${ }^{1,2}$, Fatima Ahmed Darwish Lari ${ }^{1,3}$, \\ Mohamed Ahmed Darwish Abdulla Lari ${ }^{1,4}$
}

${ }^{1}$ Faculty of Business and Technology Management, Universiti Tun Hussein Onn Malaysia (UTHM), Batu Pahat, Johor, 86400 Parit Raja, MALAYSIA

${ }^{2}$ Abu Dhabi Transmission \& Despatch Company, Abu Dhabi, UNITED ARAB EMIRATES

${ }^{3}$ Department of Municipalities and Transport (DMT), Al maamora, Abu Dhabi, UNITED ARAB EMIRATES

${ }^{4}$ Abu-Dhabi Police (GHQ), Al morour, Abu Dhabi, UNITED ARAB EMIRATES

*Corresponding Author

DOI: https://doi.org/10.30880/ijscet.2020.11.02.018

Received 30 July 2020; Accepted 30 August 2020; Available online 02 September 2020

\begin{abstract}
This paper presents an assessment of information system factors that influence the operational performance sustainability of UAE manufacturing sector. The study was conducted using quantitative approach where data was collected through the questionnaire survey and analysed statistically. A total of 41 factors of information system extracted from literature review and clustered into 4 domains namely transaction processing system; operation information system; decision support system and financial manager's workbench. The survey distributed 250 questionnaires among operations staff of UAE manufacturing industries. However, only 200 datasets were considered valid for further analysis. Ranking of factors were conducted using mean score and standard deviation. The results found that the most influential domain is decision support system having mean value of 4.19. The findings from this study give an indicator on the importance of information system toward the sustainable operational performance of the UAE manufacturing sector
\end{abstract}

Keywords: Information system, operational performance, UAE manufacturing sector

\section{Introduction}

In manufacturing, operational performance relates to the utilization of all resources (people/assets/time) to deliver lower cost and higher quality products, services to the customers in the shortest time possible (Manufacturing Institute, 2017). The performance should harmonise financial, environmental and social objectives in the delivery of the core business activities to maximise value for the manufacturing industry. Information System (IS) has become the main driver of today's manufacturing business processes. Despite information system roles to lead Operational Performance (OP) in the production sector in the UAE, many difficulties pose issues linked to the efficient use of IS for the OP (Abdelfattah $\&$ Kumar, 2015). These issues arise because of a higher degree of competition that requires strategic management of IS and OP, lack of readiness towards the digital world as well as the fourth industrial revolution (IR 4.0). Moreover, the major issues faced by IS in UAE manufacturing industries are related to maintenance, the usage and poor back up of information (Burns, 2016). Similarly, many studies in information systems of the connection between IS and OP of 
manufacturing businesses in the UAE (Li \& Zhang, 2015) and recent studies continue to find weak relationships (Ravichandran, 2018). However, other researchers found that IS investments result in significant effects on the productivity of the manufacturing industries (Brynjolfsson \& McAfee, 2014). For some researchers, information system is important for the enhancement of business value and competitive advantage (Melville et al., 2017) whereas for some others (Shin et al, 2016) "IS contributes to financial performance significantly when it is measured by a gross margin". (Liang et al., 2010) showed that both financial performance and organisational efficiency benefit from IS through the improvement of organisational capabilities.(Melville et al., 2017) observed that "Information System company value scholars that are driven by a willingness to know-how and to what extent IS implementation in manufacturing organizations leads to enhanced sustainable organizational efficiency.." Sharing the same problems, other researchers like (Tallon \& Kraemer, 2000) argue that "the lack of strong, firm-level IS impact measures" is driven by the need for in-depth understanding and assessment of IS's firm-level impacts on operational performance. Therefore, this research attempted to assess the influence of information system to operational performance in UAE manufacturing sectors for the sustainability of the manufacturing.

\section{Information System}

Information system (IS) and operational performance from the IS perspective focused on several areas including sales, production lead-time, inventory turnover and cost, utilisation of the available capacity, employee turnover. (Poltronieri et al.,2019; Yang et al.,2019; Hong et al.,2018). Operational Performance measures are usually divided into two main groups which are financial measures and non-financial (or operational) measures (Tseng et al., 2018). Financial measures, based on the economic state of a company, incorporate traditional measures (like profits, revenues, costs, financial margins, cash flow) and other more recent measures such as Economic Value Added (EVA), Cash Flow Return on Investment (CFROI) and others.

Non-financial measures, on the other hand, aim at quantifying the organisational operational performance concerning customers (e.g. customer satisfaction-retention-acquisition), employees (e.g. employee satisfaction), innovation, quality, culture and others (Abdul-Rashid et al., 2017). The above measures have been further broken down into hard measures that are easily quantifiable (such as customer acquisition, number of complaints, etc.) and soft measures that are difficult to quantify, (e.g. satisfaction). Nevertheless, having in mind that the two most desired characteristics of operational performance measures are (i) completeness, (i.e. the measure captures the 'whole truth' about operational performance) and (ii) controllability (the measure is only influenced by elements under the unit's control) (Soto-Acosta et al., 2016), it can be deduced that non-financial operational performance measures present many difficulties. The difficulty and the subjectivity inherent in measuring non-financial operational performance, along with the necessity to focus all efforts on the ultimate goal, which is to satisfy shareholders, have made some researchers suggest that operational performance measures should be purely financial.

Organisations use information system to make managerial decisions in all domains and phases of the business. Using information system, the organisation can procure, analyse and document data on all of its strategic business functions. Once an analysis performed, the company top management then bases its decisions on the reports generated by the information system. On every occasion, there are tweaks in the functioning, for which the management is capable to take remedial action instantly. Hence this study was intended to explore four (4) domains of the information system to assist the operational performance of the manufacturing sector. The information system domains are further elaborated as follow;

\subsection{Transaction Processing Systems (TPS)}

Transaction Processing System (TPS) is the most basic and elementary type of information system. With this, an organisation could record and document all of its recurrent and routine business dealings. These are transactions for example orders of raw materials, inventories, customer transactions and sales. Companies record all of their transactions using the TPS mechanism. The trends of transactions needed to be observed and controlled by recording them with the aid of TPS. For instance, if an organisation discovers that some monthly customer orders above others, it can understand that the demand during those months is favourable. The company is then capable of taking steps to handle that demand by employing and deploying more resources during those months (Rahman et.al, 2009).

\subsection{Operation Information System (OIS)}

Operations Information Systems (OIS) are tools used to devise strategies, schedule production and assemble functions. Applying these tools, a manager can decide the level of inventory and raw materials stock, and how to structure production functions. What component is to be produced after which and how the final product will be assembled is the essence of OIS. The operations manager also supervises the deployment of workers for production purposes. With effective processes in place, the company never encounters or experiences downtime situations or stock-out (Prasad \& Green, 2015). 


\subsection{Decision Support Systems (DSS)}

Senior management for executive decision-making uses DSS (decision support systems). This tool comprehensively employs the use of computers, computing tools, mathematical and scientific models for its analysis. With the DSS, the company can analyse, scrutinise and evaluate all the approaches it could deploy for use in departments such as production, sales, marketing and finance. The establishment is then able to choose the option that saves the most on costs, time, and both human and material efforts while gaining maximally (Martinsons et.al, 1999).

\subsection{Financial Manager's Workbench (FMW)}

Financial Manager's Workbench (FMW) is the application used to manage the campus' permanent budget and staffing obligations. In addition to its role as a transaction system, FMW is a highly flexible software tool well appropriated to budgeting and planning applications. The system offers access to multi-year permanent budget information at both the transaction level and summary/roll-up level aiding both analysis and research. Integration of detailed monthly distribution of payroll expense (DOPE) data with summary FIS operating ledger data to facilitate monitoring and forecasting of the current year operating budget (Martinsons et.al, 1999).

\section{Methodology}

This study adopted quantitative approach where data was collected through questionnaire survey and analysed statistically. The questionnaire was designed based on the 41 factors of information system influencing the operational performance of manufacturing industry extracted from literature review. The main content of the questionnaire is these factors which are clustered into 4 groups namely transaction processing system; operation information system; decision support system and financial manager's workbench. Respondents were required to rate each factor toward its influence to the operational performance of the manufacturing sector using 5-points Likert scale where scale 1 has no influence and scale 5 extremely influential.

A total of 250 questionnaires were distributed among operations staff of manufacturing industries in the United Arab Emirates (UAE). However, only 205 of the questionnaires were returned which indicates a response rate of $82 \%$. After the scrutinised the data, only 200 datasets were considered completed and applied for further analysis. This is considered adequate as is above $10 \%$ of the proposed sample size as according to (Creswell,2012). Respondents were given a complete arrangement of questionnaire together with an introductory letter clarifying the motivation behind the survey, the affirmation of respondent obscurity, asking for respondents to remark if any misty or troublesome inquiries are found and to suggest to enhance the outline of the survey. The data collected from the survey was analysed descriptively for reliability test of Cronbach's Alpha and ranking of factors using mean index and standard deviation. The reliability test results with Cronbach's alpha are as demonstrated in Table 1.

Table 1 - Reliability Result

\begin{tabular}{llcc}
\hline \multicolumn{1}{c}{ Group of factors } & \multicolumn{1}{c}{ No. of group } & No. of factors & Cronbach's Alpha \\
\hline \multirow{2}{*}{ Transaction Processing System } & Rapid Response & 3 & \\
& Reliability & 5 & 0.898 \\
\multirow{2}{*}{ Operation Information System } & Control & 4 & \multirow{2}{*}{0.882} \\
\multirow{2}{*}{ Decision Support System } & $\quad$-NA- & 7 & \multirow{2}{*}{0.823} \\
& Information\& System Quality & 7 & \\
& Ease of Use & 3 & \\
Financial Manager's Workbench & Decision Satisfaction & 5 & 0.885 \\
& Permanent Budget & 3 & \\
& Staffing List & 2 & \\
& Operating Budget & 2 & \\
\hline
\end{tabular}

Table 1 indicates that the Cronbach alphas are above 0.8 which is higher than the threshold value of 0.7 and this implies that the questionnaire is reliable for further analysis as recommended by (Hair et al., 2010).

\section{Result and Analysis}

Collected data for the factors was analyzed with mean value and standard deviation which were used to rank accordingly to the significance level of each factors toward the operational performance of the manufacturing sector. There are four domains which are Transaction Processing System; Operations Information System; Decision Support Systems and Financial Manager's Workbench. 


\subsection{Transaction Processing System}

In Transaction Processing System domain, there three group namely rapid respond, reliability and control. Ranking of the factors in each group and the group rank are presented in Table 2.

Table 2 - Ranking of The Factors in Transaction Processing System [TPS] Domain

\begin{tabular}{lllcc}
\hline Code & \multicolumn{1}{c}{ Factors influencing operational performance } & Mean & $\begin{array}{c}\text { Std. } \\
\text { Deviation }\end{array}$ & Rank \\
& & & 1.773 & $\mathbf{3}$ \\
RR1 & Transactions are performed automatic via IT & 3.86 & 1.591 & $\mathbf{1}$ \\
RR2 & Allows more efficient job performance & 4.23 & $\mathbf{2}$ \\
RR3 & There is an immediate feedback response & 4.16 & $\mathbf{4 . 0 8}$ & \\
\hline Group & Rapid Response & 4.11 & 1.538 & $\mathbf{3}$ \\
\hline RL1 & Created room for new skills development & 4.46 & 1.513 & $\mathbf{1}$ \\
RL2 & Increases demand for more computer systems & 4.38 & 1.473 & $\mathbf{2}$ \\
RL3 & Information can sometimes be misleading & 3.80 & 1.500 & $\mathbf{5}$ \\
RL4 & Sustomers/operators & 3.89 & 1.458 & $\mathbf{4}$ \\
RL5 & Errors can be made during entry, gathering and retrieval & $\mathbf{4 . 1 3}$ & & $\mathbf{1}$ \\
\hline Group & Reliability & 4.39 & 1.397 & $\mathbf{2}$ \\
\hline CL1 & There is a continuous need for data security & 4.29 & 1.340 & $\mathbf{4}$ \\
CL2 & Data are often stolen or modified by a third party & 4.15 & 1.298 & $\mathbf{3}$ \\
CL3 & Every transaction must be processed in the same way & 4.24 & 1.237 \\
CL4 & Saves money for not recruitment of more staff & $\mathbf{4 . 2 7}$ & & \\
\hline Group & Control & $\mathbf{4 . 1 6}$ & & \\
\hline
\end{tabular}

The results from the table 2 indicates that control group is the most influential toward the operational performance. However, for the factor, the most influential is CL1 in the control group having mean score of 4.39 which is a continuous need for data security.

\subsection{Operations Information System}

In this domain, there is no group and comprises of seven (7) factors with the code OIS1 until OIS7. The results of the ranking analysis are as in table 3

Table 3 - Ranking of The Factors in Operations Information System [OIS] Domain

\begin{tabular}{llccc}
\hline Code & \multicolumn{1}{c}{ Factors influencing operational performance } & Mean & $\begin{array}{c}\text { Std. } \\
\text { Deviation }\end{array}$ & Rank \\
\hline OIS1 & It allows employees to increase engagement & 3.96 & 1.239 & $\mathbf{6}$ \\
OIS2 & $\begin{array}{l}\text { It provides a clearer view on how it affects every ones' role it } \\
\text { enables integration of operational processes }\end{array}$ & 3.94 & 1.277 & $\mathbf{7}$ \\
& Teams work are integrated into organizational supporting & 3.97 & 1.221 & $\mathbf{5}$ \\
OIS3 & technology & 4.20 & 1.554 & $\mathbf{4}$ \\
OIS4 & Increases operational efficiency & 4.22 & 1.629 & $\mathbf{3}$ \\
OIS5 & Reduces ambiguity in accountability & 4.23 & 1.479 & $\mathbf{2}$ \\
OIS6 & Enhances interaction between various business units & 4.34 & 1.441 & $\mathbf{1}$ \\
OIS7 & Reduces operating risks & $\mathbf{4 . 1 8}$ & & \\
\hline Group & Operations Information System [OIS] & \multicolumn{4}{c}{ Mean score of the domain } & $\mathbf{4 . 1 2}$ & \\
\hline
\end{tabular}

\subsection{Decision Support Systems}

In this Decision Support Systems domain, there are three (3) groups which are Information\& System Quality; Ease of Use and Decision Satisfaction. The results of the ranking analysis are as in table 4 
Table 4 - Ranking of The Factors in Decision Support Systems [DSS] Domain

\begin{tabular}{|c|c|c|c|c|}
\hline Code & Factors influencing operational performance & Mean & $\begin{array}{c}\text { Std. } \\
\text { Deviation }\end{array}$ & Rank \\
\hline ISQ1 & Information from the DSS is easy to understand & 3.48 & 1.464 & 7 \\
\hline ISQ2 & The DSS provides sufficient information & 3.67 & 1.487 & 4 \\
\hline ISQ3 & $\begin{array}{l}\text { The DSS provide reports that seem to be just about exactly } \\
\text { what I need }\end{array}$ & 3.50 & 1.523 & 6 \\
\hline ISQ4 & The DSS provide up-to-date information & 3.64 & 1.409 & 5 \\
\hline ISQ5 & The DSS allows information to be readily accessible to me & 4.34 & 1.618 & 1 \\
\hline ISQ6 & $\begin{array}{l}\text { The DSS user interface can be easily adapted to one's } \\
\text { personal approach. } \\
\text { All data within the DSS is fully integrated and consistent }\end{array}$ & 4.28 & 1.630 & 2 \\
\hline ISQ7 & $\begin{array}{l}\text { ISQ8: The DSS can be easily modified, corrected or } \\
\text { improved }\end{array}$ & 4.16 & 1.427 & 3 \\
\hline Group & Information\& System Quality & 3.87 & & \\
\hline EU1 & Learning to operate the DSS is easy for me & 4.29 & 1.354 & 3 \\
\hline EU2 & $\begin{array}{l}\text { Interacting with the DSS does not require a lot of my mental } \\
\text { effort }\end{array}$ & 4.67 & 1.403 & 1 \\
\hline EU3 & I find it easy to get the DSS to do what I want it to do & 4.38 & 1.798 & 2 \\
\hline Group & Ease of Use & 4.45 & & \\
\hline DS1 & Using the DSS enables me to accomplish job's tasks & 4.49 & 1.561 & 3 \\
\hline DS2 & $\begin{array}{l}\text { Using the DSS improves my ability to make good and } \\
\text { effective decisions }\end{array}$ & 4.51 & 1.715 & 2 \\
\hline DS3 & $\begin{array}{l}\text { The DSS enhances my awareness and recall of job-related } \\
\text { information }\end{array}$ & 4.32 & 1.748 & 5 \\
\hline DS4 & The DSS has met my expectations & 4.57 & 1.631 & 1 \\
\hline DS5 & $\begin{array}{l}\text { Overall, I'm satisfied with the DSS ability to enables me to } \\
\text { make better decisions }\end{array}$ & 4.36 & 1.677 & 4 \\
\hline \multirow[t]{2}{*}{ Group } & Decision Satisfaction & 4.45 & & \\
\hline & Mean score of the domain & 4.19 & & \\
\hline
\end{tabular}

\subsection{Financial Manager's Workbench}

In this domain there three (3) groups also which are Permanent Budget; Staffing List and Operating Budget. The results of the ranking analysis of this domain are as table 5.

Table 5 - Ranking of The Factors in Financial Manager's Workbench [FMW] Domain

\begin{tabular}{|c|c|c|c|c|}
\hline Code & Factors influencing operational performance & Mean & $\begin{array}{c}\text { Std. } \\
\text { Deviation }\end{array}$ & Rank \\
\hline PM1 & $\begin{array}{l}\text { Users have the ability to post permanent budget transactions } \\
\text { online }\end{array}$ & 3.96 & 1.278 & 3 \\
\hline PM2 & Users see real-time updates to their permanent budgets & 4.02 & 1.224 & 2 \\
\hline \multirow[t]{2}{*}{ PM3 } & $\begin{array}{l}\text { Users have access to } 2-3 \text { year budgets information at both the } \\
\text { transaction level and summary }\end{array}$ & 4.03 & 1.223 & 1 \\
\hline & Permanent Budget & 4.00 & & \\
\hline SL1 & $\begin{array}{l}\text { Users have the ability to add, modify and delete their open } \\
\text { provisions }\end{array}$ & 3.90 & 1.176 & 2 \\
\hline \multirow[t]{2}{*}{ SL2 } & $\begin{array}{l}\text { Users can monitor their Staffing List on demand through } \\
\text { current payroll }\end{array}$ & 3.95 & 1.150 & 1 \\
\hline & Staffing List & 3.93 & & \\
\hline OB1 & $\begin{array}{l}\text { FMW Web integrates detailed monthly distribution of payroll } \\
\text { expense (DOPE) }\end{array}$ & 4.00 & 1.195 & 2 \\
\hline \multirow[t]{3}{*}{ OB2 } & $\begin{array}{l}\text { FMW Facilitate monitoring and forecasting of the current } \\
\text { year operating budget }\end{array}$ & 4.05 & 1.198 & 1 \\
\hline & Operating Budget & 4.03 & & \\
\hline & Mean score of the domain & 3.99 & & \\
\hline
\end{tabular}

Table 5 shows that the mean values of all the factors range from 3.48 to 4.67 . This indicates that all the factors have high influence toward the operational performance of the manufacturing sector of UAE. This is because referring to the 5 -point Likert scale where 1 has no influence where 5 is extremely influence and 3 has influence. Since all the factors 
having means score equal and more than 3.48, thus all the factors are having influential on the operational performance of the manufacturing.

\section{Conclusion}

This study investigated the factors of information system that influence the operational performance of the UAE manufacturing sector. It was conducted using quantitative approach where data was collected through the questionnaire survey and analysed statistically. The 41 factors of information system extracted from literature review and clustered into 4 domains namely transaction processing system; operation information system; decision support system and financial manager's workbench that affect the operational performance were investigated. The results found that the most influential domain is decision support system having mean value of 4.19. The findings from this study give an indicator on the importance of information system toward the sustainable operational performance of the UAE manufacturing sector.

\section{Acknowledgement}

The authors would like to thank Universiti Tun Hussein Onn Malaysia, Abu Dhabi Transmission \& Despatch Company, Department of Municipalities and Transport (DMT), Al maamora and Abu-Dhabi Police (GHQ), Al morour, Abu Dhabi, United Arab Emirates.

\section{References}

Abdelfattah, M. A., \& Kumar, A. T. (2015). A web-based GIS enabled soil information system for the United Arab Emirates and its applicability in agricultural land use planning. Arabian Journal of Geosciences, 8(3), 1813-1827

Abdul-Rashid, S. H., Sakundarini, N., Raja Ghazilla, R. A., \& Thurasamy, R. (2017). The impact of sustainable manufacturing practices on sustainability performance. International Journal of Operations \& Production Management, 37(2), 182-204

Brynjolfsson, E., \& McAfee, A. (2014). The second machine age: Work, progress, and prosperity in a time of brilliant technologies. WW Norton \& Company

Burns, P. (2016). Entrepreneurship and small business. Palgrave Macmillan Limited

Creswell, J. W. (2012). Educational research: Planning, conducting, and evaluating quantitative and qualitative research (4th ed.). Boston, MA: Pearson

Hair, J. F., William, C. B., Barry, J. B., \& Anderson, R. E. (2010). Multivariate Data Analysis: Englewood Cliffs, NJ: Prentice Hall

Hong, J., Zhang, Y., \& Ding, M. (2018). Sustainable supply chain management practices, supply chain dynamic capabilities, and enterprise performance. Journal of Cleaner Production, 172, 3508-3519. Implementing and Measuring Key Principles. Journal of General Management, 29, 1 (Autumn), pp.15-31

Li, T. and Zhang, H. (2015), "Information sharing in a supply chain with a make-to-stock manufacturer", Omega, Vol. 50 No. 2, pp. $115-125$

Liang, T. P., You, J. J., \& Liu, C. C. (2010). A resource - based perspective on information technology and firm performance: a meta analysis. Industrial Management \& Data Systems

Manufacturing report 2017, https://www.themanufacturinginstitute.org/research/reports/

Martinsons, M., Davison, R., Tse, D. (1999). The balanced scorecard: A foundation for the strategic management of information systems. Decision Support Systems, Volume 25, Issue 1, February 1999, pp.71-88

Melville, C. et al. (2017) Definitions, measurement and prevalence of sedentary behaviour in adults with intellectual disabilities - a systematic review. Preventive Medicine, 97, pp. 62-71. (doi:10.1016/j.ypmed.2016.12.052)

Paul P. Tallon, Kenneth L. Kraemer \& Vijay Gurbaxani (2000) Executives' Perceptions of the Business Value of Information Technology: A Process-Oriented Approach, Journal of Management Information Systems, 16:4, 145-173, 
Pedro Soto-AcostaSimona PopaDaniel Palacios-Marqués, E-business, organizational innovation and firm performance in manufacturing SMEs: an empirical study in Spain, September 2016Technological and Economic Development of Economy 22(6):1-20

Poltronieri, C. F., Ganga, G. M. D., \& Gerolamo, M. C. (2019). Maturity in management system integration and its relationship with sustainable performance. Journal of cleaner production, 207, 236-247

Prasad, A., \& Green, P. (2015). Organizational competencies and dynamic accounting information system capability: impact on AIS processes and firm performance. Journal of Information Systems, 29(3), 123-149

Rahman, A., Bennet, D., \& Sohal, A. (2009). Transaction attributes and buyer supplier relationships in AMT acquisitions and implementation: the case of Malaysia. International Journal of Production Research, 47(9), 2257-2278

Ravichandran, T. (2018). Exploring the relationships between IT competence, innovation capacity and organizational agility. The Journal of Strategic Information Systems, 27(1), 22-42

Shin, K. J., Shin, H. J., Lee, S. H., Song, W. C., Koh, K. S., \& Gil, Y. C. (2016). Emerging points of the supraorbital and supratrochlear nerves in the supraorbital margin with reference to the lacrimal caruncle: implications for regional nerve block in upper eyelid and dermatologic surgery. Dermatologic Surgery, 42(8), 992-998

Tseng, M. L., Wu, K. J., Chiu, A. S., Lim, M. K., \& Tan, K. (2018). Service innovation in sustainable product service systems: Improving performance under linguistic preferences. International Journal of Production Economics, 203, 414425

Yang, G. L., Fukuyama, H., \& Chen, K. (2019). Investigating the regional sustainable performance of the Chinese real estate industry: A slack-based DEA approach. Omega, 84, 141-159 